KAVAKA53: 92-95(2019)

doi:

\title{
New records of genus Marasmius (Marasmiaceae) from India
}

\author{
Munruchi Kaur and Aakriti Gupta \\ Department of Botany, Punjabi University, Patiala-147002, India \\ Corresponding author Email: munruchi@gmail.com
}

(Submitted on November 15, 2019; Accepted on December 25,2019)

\begin{abstract}
Three species of Marasmius, viz. M. fulvoferrugineus Gilliam, M. pallescens Murrill and M. pseudobambusinus Desjardin are recorded from India. Comprehensive descriptions, photographs and discussion on each species is provided.
\end{abstract}

KEYWORDS: Broom cells, Sicci, non- institious, institious.

\section{INTRODUCTION}

Genus Marasmius Fr., (Marasmiaceae) is a saprotrophic genus with ca. 500 species known world over (Kirk et al., 2008). In India 84 species are currently known (Upadhyay et al., 2017; Bhosale et al., 2019; Chakraborty, 2019). The genus is represented by persistent and marcescent carpophores having a unique ability to revive when rehydrated. Morphologically, the genus is characterized by convex to campanulate sporophores with long wiry either insititious or non-insititious stipes. Microscopically, this genus is represented by inamyloid basidiospores, nonhymeniform to hymeniform pileus cuticle with setulose or non-setulose broom cells. Characters like stipe insertion, presence or absence of mycelial mat, amyloidity of the basidiospores and the type of pileipellis elements are important taxonomic features in the infrageneric delimitation of marasmoid genera. Present paper provides detailed descriptions of three species of genus Marasmius viz. $M$. fulvoferrugineus Gilliam, M. pallescens Murrill and $M$. pseudobambusinus Desjardin, so far not known from India.

\section{MATERIALS AND METHODS}

Various localities of North India were visited during the monsoon season for collection of the specimens. Healthy and fresh fruit bodies growing on leaf litter were collected. Collection and preservation of carpophores was done using methodology given by Atri et al. (2005, 2017). Color terminology used is that of Kornerup and Wanscher (1978). All the collections were deposited in the Herbarium of Botany Department, Punjabi University Patiala (Punjab), India (PUN).

\section{TAXONOMY}

Marasmius fulvoferrugineus Gilliam, Mycotaxon 4 (1): 82 (1976).

Figs. 1-5

Carpophores $0.6-4.0 \mathrm{~cm}$ in height. Pileus $0.4-0.8 \mathrm{~cm}$ broad, convex to campanulate; umbonate, umbo acute; margin irregular, splitting at maturity, striate up to the centre; scales absent; surface dark brown (6D4) when young becoming greyish orange (6B3) when mature, dry. Lamellae non-collariate, free, subdistant; equal, narrow (up to $0.1 \mathrm{~cm}$ ), creamish white (1A2), unchanging; gill edges smooth, normal; lamellulae absent. Stipe central, $0.5-3.9 \mathrm{~cm}$ long, up to $0.1 \mathrm{~cm}$ broad, equal in diameter throughout, wiry; surface light brown (7D5) near the apex to brown (7D7) in the middle and towards the base, unchanging; smooth, scales absent,

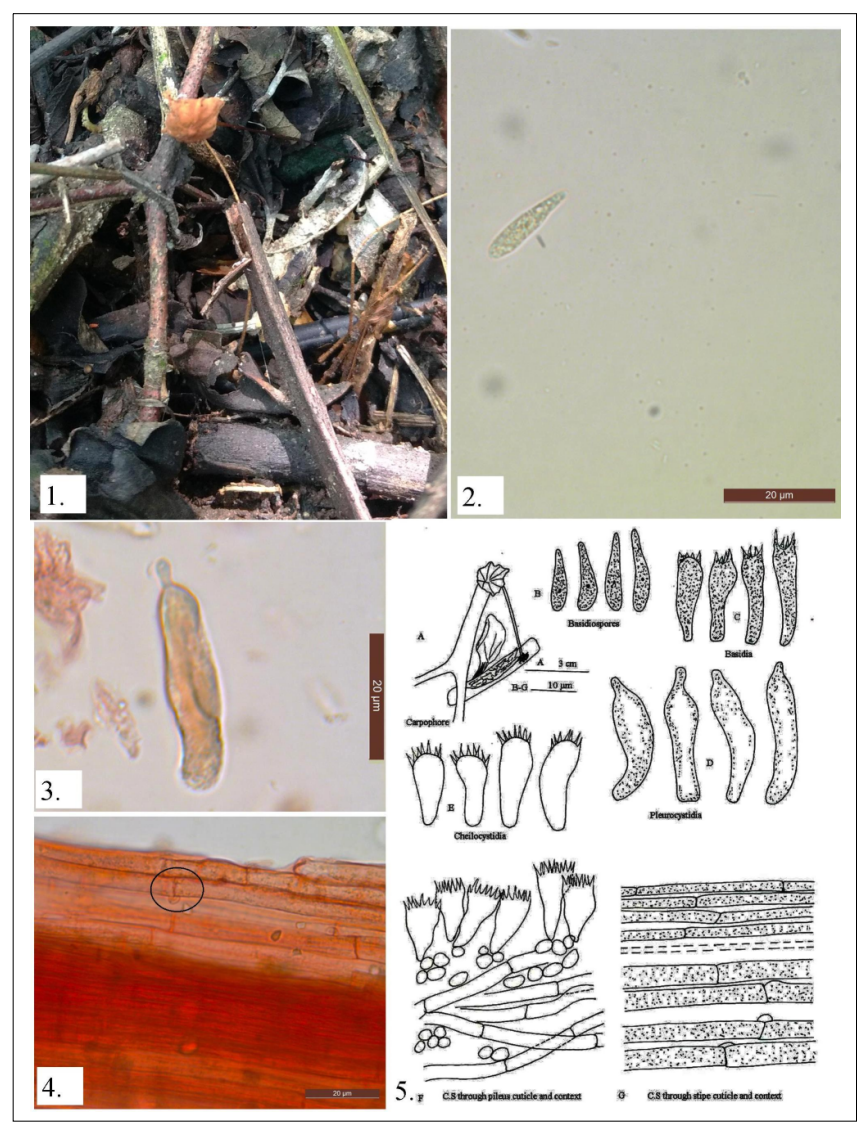

Figs. 1-5 M. fulvoferrugineus: 1. Carpophore growing solitary on dicotyledonous leaves, 2. Photomicrograph showing elongated basidiospore, 3. Fusoid ventricose pleurocystidium with tubular tip, 4. C.S through stipe context showing clamp connection, 5 (A-G) A. Carpophore, B. Basidiospores, C. Basidia, D. Pleurocystidia, E. Cheilocystidia, F. C.S through pileus cuticle and context showing epicuticular broom cells, G. C.S through stipe cuticle and context showing clamp connection.

non-institious; white mycelial mat present at the base of the stipe, solid, exannulate. Flesh less than $0.1 \mathrm{~cm}$ thick, white, unchanging; odor mild; taste mild.

Basidiospores $15.4-18.0 \times 3.5-4.9 \mu \mathrm{m},(\mathbf{Q}=3.4)$, elongated, inamyloid, thin walled, granular; apiculate, apiculus up to $0.7 \mu \mathrm{m}$ long. Basidia $19.6-28.0 \times 5.0-5.6$ $\mu \mathrm{m}$, clavate, granular; tetrasterigmate, sterigmata $3.5-5.0$ 
$\mu \mathrm{m}$ long. Pleurocystidia $28.0-44.8 \times 7.0-11.2 \mu \mathrm{m}$, fusoidventricose with beaked and tubular tips, granular, protruding out of the basidial layer, abundant. Lamella edge sterile. Cheilocystidia abundant $18.2-25.2 \times 8.4-9.8 \mu \mathrm{m}$ (including setules), clavate with apical setules, $6-7$ setules per cystidia, hyaline. Hymenophoral trama regular. Pileus cuticle made up of a uniform layer of dextrinoid broom cells measuring $15.4-25.2 \times 9.1-9.8 \mu \mathrm{m}$, bearing $7-8$ setules per broom cell; context made up of $4.2-5.6 \mu \mathrm{m}$ broad, septate, hyphae intermixed with $5.0-9.0 \mu \mathrm{m}$ broad cells; pileocystidia absent. Stipe cuticle hyphal, made up of longitudinally arranged, $3.5-4.2 \mu \mathrm{m}$ broad, septate hyphae; caulocystidia absent; stipe trama hyphal, made up of 5.6-7.0 $\mu \mathrm{m}$ broad, septate hyphae. Clamp connections present throughout.

Collection examined: Jammu and Kashmir: Jasrota Wildlife Sanctuary, Kathua (550 m) 32²9'06”N - 75²4'20"E, growing scattered on dead and decomposed dicotyledonous leaves, in mixed forest, Aakriti Gupta, PUN 10768, 15 August, 2017.

Distribution and ecology: Marasmius fulvoferrugineus was found growing either scattered or gregariously in mixed woods from mid- July to mid- October in the North- Eastern United States and adjacent Canada (Gilliam, 1976). The present collection was found growing scattered on dicotyledonous leaf litter and fallen twigs during mid-August in mixed forests of Jasrota Wildlife Sanctuary Jammu and Kashmir, at an altitude of $550 \mathrm{~m}$.

Remarks: The above examined agaric matches well with the description of Marasmius fulvoferrugineus provided by Gilliam (1976). This species is different from the closely allied species, Marasmius siccus (Schwein.) Fr., in morphological and anatomical features, which is characterized in having smaller pileus with more orange shade and larger basidiospores (16.0 - $21.0 \mu \mathrm{m})$. Marasmius fulvoferrugineus is reported for the first time from India.

Marasmius pallescens Murrill, North American Flora 9 (4): 261 (1915).

Figs. 6-9

Carpophores $4.5-6.3 \mathrm{~cm}$ in height. Pileus up to $1.9-3.3 \mathrm{~cm}$ broad, convex to campanulate; umbonate, umbo broad; margin irregular, striate up to the centre; scales absent; surface reddish brown (8D7) in young carpophores becoming brownish orange (7C4) at maturity, dry. Lamellae noncollariate, adnexed, distant, moderately broad (up to $0.4 \mathrm{~cm}$ ); yellowish white (1A2), unchanging; lamellae edges smooth, normal; lamellulae absent. Stipe central, $4.4 \quad 6.0 \times 0.1 \mathrm{~cm}$ broad, equal, surface yellowish white (1A2) near the apex, brownish orange (5C4) in the middle and dark brown (7F4) at the base, unchanging, smooth, non-institious; white mycelial mat present towards the base of the stipe, solid, exannulate. Context membranous, thin, white, unchanging; odor mild; taste mild.

Basidiospores $14.0-19.6 \times 3.5-4.2 \mu \mathrm{m},(\mathbf{Q}=4.0)$, cylindric to elongated, inamyloid, thin walled, fusoid, hyaline; apiculate, apiculus up to $0.7 \mu \mathrm{m}$ long. Basidia $14.0-22.4 \times$ $6.3-7.0 \mu \mathrm{m}$, clavate, hyaline; tetrasterigmate, sterigmata 3.5 $-4.2 \mu \mathrm{m}$ long. Pleurocystidia $29.4-42.0 \times 5.6-8.4 \mu \mathrm{m}$,

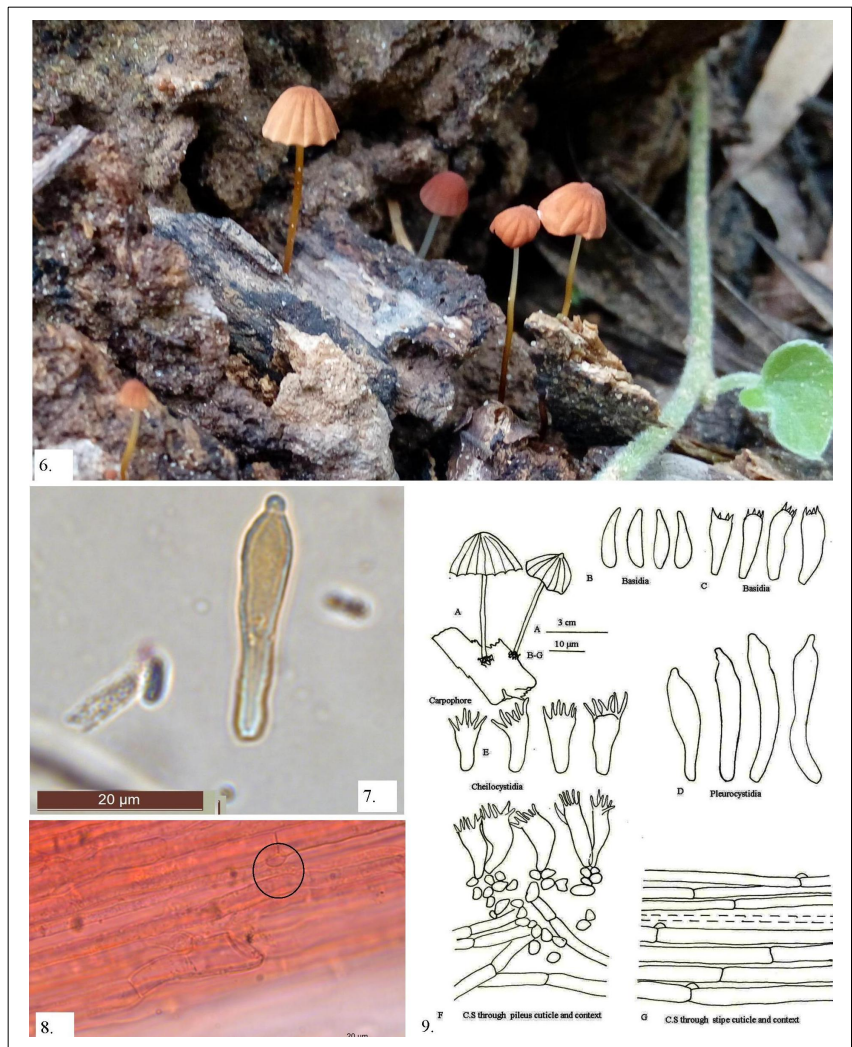

Figs.6-9 M. pallescens: 6. Carpophore growing on decomposed wooden logs, 7. Fusoid-ventricose pleurocystidium with capitate tip, 8. C.S through stipe cuticle showing clamp connection, 9. (A-G) A. Carpophores, B. Basidiospores, C. Basidia, D. Pleurocystidia, E. Cheilocystidia, F. C.S through pileus cuticle and context showing clavate epicuticular broom cells, G. C.S through stipe cuticle and context showing clamp connection.

fusoid ventricose to clavate with blunt and capitate tips, few mucronate with yellow refractive contents, hyaline to few granular at the apex, protruding out of the hymenium, abundant. Lamellae edges sterile. Cheilocystidia 19.6-23.8 $\times 7.0-8.4 \mu \mathrm{m}$ (including setules), clavate with broom like projections, $5-6$ setules per cystidia, hyaline, abundant. Hymenophoral trama regular. Pileus cuticle made up of a regular turf of siccus shaped broom cells $15.4-22.4 \times 5.6-$ $8.4 \mu \mathrm{m}$ in size, bearing $6-7$ setules per broom cell; context made up of $4.2-5.6 \mu \mathrm{m}$ broad, septate, hyphae intermixed with $4.2-7.0 \mu \mathrm{m}$ broad cells ; pileocystidia absent. Stipe cuticle hyphal, made up of longitudinally arranged, 3.5 - 4.2 $\mu \mathrm{m}$ broad, septate hyphae; caulocystidia absent; stipe trama hyphal, made up of $5.2-7.0 \mu \mathrm{m}$ broad, septate, hyphae. Clamp connections present throughout.

Collection examined: Jammu and Kashmir: Mansar along road side, $(431 \mathrm{~m}) 32^{\circ} 36^{\prime} 06^{\prime \prime} \mathrm{N}$ - 75'14'28"E, growing scattered on decomposed wooden logs, in mixed forest, Aakriti Gupta, PUN 10770, 29August, 2017.

Distribution and ecology: Marasmius pallescens was reported from various localities of Lesser Antilles including Martinique (Pegler, 1983). Wannathes et al. (2009) collected M. pallescens from Northern Thailand growing scattered to 
gregarious on dicotyledonous leaves.

Remarks: Present collection matches with the description given for $M$. pallescens Murrill (Wannathes et al., 2009; Pegler, 1983). However, Wannathes et al. (2009) quoted slightly larger spores $(16.0-19.0 \times 4.0-5.0 \mu \mathrm{m})$. Pegler (1983) reported slightly smaller spores $(12.0-17.5 \times 3.0-5.0$ $\mu \mathrm{m})$. In the present collection, the cheilocystidia are comparatively larger i.e. 19.6 - $23.8 \times 7.0-8.4 \mu \mathrm{m}$ rather than those provided by Wannathes et al. (2009) and Pegler (1983). This species is so far not recorded from India.

Marasmius pseudobambusinus Desjardin Mycologia 83(1): 30 (1991).

Figs.10-13

Carpophores $4.3-4.5 \mathrm{~cm}$ in height. Pileus $0.4-0.7 \mathrm{~cm}$ broad, convex, campanulate in some; broadly umbonate, margin irregular, striate up to the centre; smooth; surface brownish orange (6C4) with pale red (7A3) to pastel red (7A4) tinge at the centre, dry. Lamellae non- collariate, adnate, yellowish white (1A2), subdistant, narrow (up to $0.1 \mathrm{~cm}$ ), unchanging; edges smooth, normal, lamellulae absent. Stipe central, 4.3 $4.5 \mathrm{~cm}$ long, up to $0.2 \mathrm{~cm}$ broad, equal, wiry; surface reddish brown (8D5), unchanging; smooth, non-institious; white mycelial mat present at the base of the stipe, solid, exannulate. Context less than $0.1 \mathrm{~cm}$ thick, white, unchanging. Odour mild; taste mild.

Basidiospores 14.0 - $19.7 \times 4.2-5.0 \mu \mathrm{m},(\mathbf{Q}=4.0)$, cylindrical to few curved, inamyloid, thin- walled, granular; apiculate, apiculus up to $0.7 \mu \mathrm{m}$ long. Basidia $28.0-36.4 \times 5.6-7.0 \mu \mathrm{m}$, clavate, tetrasterigmate; sterigmata 3.5 - $4.2 \mu \mathrm{m}$ long. Pleurocystidia 36.4 - $54.6 \times 6.3-8.4 \mu \mathrm{m}$, fusoid ventricose to cylindrical, capitate with constricted tips, wavy in outline, abundant with yellow refractive contents, granular, protruding out of the basidial layer. Lamellae edges sterile. Cheilocystidia 8.4 - $15.4 \times 7.0$ - $8.4 \mu \mathrm{m}$ (excluding setules), abundant, clavate with verrucose apical setules, 6 - 7 setules per cystidia. Hymenophoral trama regular. Pileus cuticle made up of a regular turf of siccus shaped broom cells measuring $14.0-18.2 \times 5.6-6.3 \mu \mathrm{m}$ in size, bearing $6-7$ verrucose setules per broom cell. Context made up of $4.2-5.0$ $\mu \mathrm{m}$ broad, septate, hyphae intermixed with $5.0-8.4 \mu \mathrm{m}$ broad cellular elements. Pileocystidia absent. Stipe cuticle hyphal, made up of longitudinally arranged, 4.2 - $5.0 \mu \mathrm{m}$ broad, septate hyaline hyphae. Caulocystidia absent. Stipe context hyphal, made up of 5.0 - $5.6 \mu \mathrm{m}$ broad, septate hyphae. Clamp connections present throughout.

Collection examined: Himachal Pradesh: Kullu, Jibhi Forest, $(2468 \mathrm{~m}) 31^{\circ} 40^{\prime} 55^{\prime \prime} \mathrm{N}-7^{\circ} 13^{\prime} 41^{\prime \prime E}$, growing scattered in groups on gymnosperm needles and dicotyledonous leaves, Aakriti Gupta, PUN 10771, 3 September, 2017.

Distribution and ecology: Desjardin (1991) recorded Marasmius pseudobambusinus growing gregarious on senescent leaves of various grasses in open lawns, during the month of May to August from Southern Appalachian Mountains of North America. In Himachal Pradesh it is found growing scattered on mixed leaf litter during September.

Remarks: The above collection matches well with the details of Marasmius pseudobambusinus (Desjardin, 1991). This

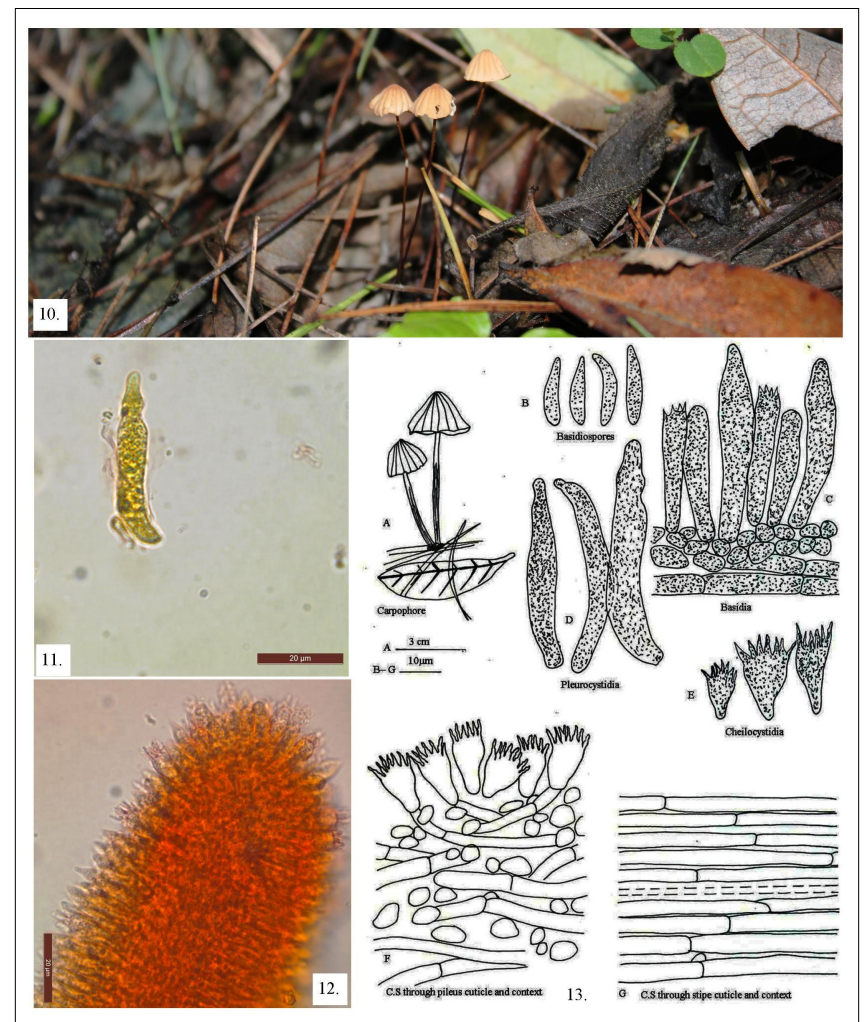

Figs. 10-13 M. pseudobambusinus: 10. Carpophore growing on gymnosperm needles and dicot leaves, 11. Fusoidventricose pleurocystidium with capitate to constricted tip and yellow refractive contents, 12. Gill edge showing siccus shaped cheilocystidia, 13. (A-G) A. Carpophores, B. Basidiospores, C. Basidia, D. Pleurocystidia, E. Cheilocystidia, F. C.S through pileus cuticle and context showing clavate epicuticular broom cells, G. C.S. through stipe cuticle and context showing clamp connection.

species is closely related to $M$. bambusinus Fr. and $M$. bambusiniformis Singer but markedly differs from both the species. M. pseudobambusinus has medium sized carpophores whereas they are larger in M. bambusinus and smaller in M. bambusiniformis. It also differs in its spore size and shape of pleurocystidia. The spore length of $M$. bambusinus is $16.1-19.3 \mu \mathrm{m}$ while that of $M$. bambusiniformis is $15.0-19.0 \mu \mathrm{m}$. But in $M$. pseudobambusinus the spore length is $14.0-19.7 \mu \mathrm{m}$. Further, the pleurocystidia in $M$. pseudobambusinus are fusoid, apically constricted and wavy in outline but capitate in M. bambusinus and totally absent in M. bambusiniformis. This is a new record for India.

\section{ACKNOWLEDGEMENT}

Thanks are due to the Head, Department of Botany, Punjabi University, Patiala for providing laboratory facilities and DSA-I (UGC) and FIST (DST) for financial assistance during the course of this work.

\section{REFERENCES}

Atri, N. S., Kaur, A. and Kour, H. 2005. Wild mushroomsCollection and identification. In: Frontiers 
Mushroom Biotechnology, (Eds.: Rai, R.D., Upadhyay, R.C. and Sharma, S.R.), N.R.C.M. (ICAR), Chambaghat, Solan. 9-26.

Atri, N. S., Kaur, M. and Sharma, S. 2017. Characterization of Lamellate Mushrooms. In: Developments in Fungal Biology and Applied Mycology. (Eds.: Satyanarayana, T., Deshmukh, S. and Johri, B.) Springer, Singapore. pp. 471-500.

Bhosale, A. K., Kadam, V., Bankar, P., Shitole, S., Chandankar, S., Wagh, S. and Kanade, M. B. 2019. Checklist of Macro-Fungi from Baramati Area of Pune District, MS, India. Int. J. Curr. Microbiol. App. Sci 8 (7): $2187-$ 2192.

Chakraborty, T. K. 2019. Macrofungi of Dakshin Dinajpur district of West Bengal, India. NeBIO. 10 (2): 66-76.

Desjardin, D.E. 1991. Studies on Marasmius from eastern North America. IV. Additions to sect. Sicci. Mycologia 83 (1):30-39
Gilliam, M.S. 1976. The genus Marasmius in the northeastern United States and adjacent Canada. Mycotaxon 4:1 - 144.

Kirk, P. F., Cannon, P. F., Minter, D. W. and Stalpers, J. A. 2008. 'Dictionary of the Fungi' $\left(10^{\text {th }}\right.$ ed.), CABI Bioscience, CAB International, U.K.

Kornerup, A. and Wanscher, J. H. 1978. Methuen Handbook of Colour, $3^{\text {rd }}$ ed., Eyre Methuen, London

Pegler, D. N. 1983. Agaric Flora of the Lesser Antilles. Kew Bull. Addit. Series 9: 1-668.

Upadhyay, R. C., Verma, B., Sood, S., Atri, N. S., Lakhanpal, T. N. and Sharma, V. P. 2017. Documentary of Agaricomycetous mushrooms of India. Jaya Publishing House, Delhi. pp. 1-193.

Wannathes, N., Desjardin, D.E., Hyde, K.D., Perry, B.A. and Lumyong, S. 2009. A monograph of Marasmius (Basidiomycota) from Northern Thailand based on morphological and molecular (ITS sequences) data. Fungal diversity 37: 209-306. 